\title{
Calcium Carbonate Sedimentation in THE GLOBAL OCEAN: LiNKages BetweEN THE NeRITIC AND PELAGIC ENVIRONMENTS
}

\author{
By John D. Milliman and André W. Droxler
}

\begin{abstract}
A global
\end{abstract}

understanding of the

production,

preservation, and

accumulation of

calcium carbonate

thus necessitates

understanding both

the neritic and pelagic

systems . . .
$\mathrm{O}$ THER THAN fluvial sediment, calcium carbonate $\left(\mathrm{CaCO}_{3}\right)$ is the greatest source of sediment in the present-day ocean. Interest in carbonate sedimentation extends beyond geologists because the carbonate system involves biologic and geochemical processes. Carbonate production, for example, releases $\mathrm{CO}_{2}$ but its accumulation becomes a major sink for inorganic carbon.

Unlike fluvial sediments, modern carbonates accumulate more or less equally in the neritic and pelagic environments. Neritic carbonates (benthic) are characterized by rapid production of (mostly) metastable aragonite and magnesian calcite; pelagic production of (primarily) calcite in the open ocean occurs at much slower rates but over much larger areas than does neritic production (Table 1). A global understanding of the production, preservation, and accumulation of calcium carbonate thus necessitates understanding both the neritic and pelagic systems, even though communication between researchers in the two subdisciplines often has been minimal.

In an effort to promote closer communication between neritic and pelagic researchers, an NSFfunded workshop was held in Upper Brandon, Virginia last autumn (13-16 October 1994), which brought together carbonate sedimentologists, $\mathrm{mi}$ cropaleontologists, geochemists, and modelers. Workshop themes emphasized the role and relative importance of calcium carbonate in neritic and pelagic environments, linkages between the two in determining a global carbonate budget, and future research directions that might reduce uncertainties in our understanding of the global carbonate system.

Although we delved into many topics in which our knowledge ranged from adequate to poor, three topics seemed to attract the most interest: how well we can quantify the global carbonate budget, whether the oceans are in steady state, and

John D. Milliman, School of Marine Science, College of William and Mary, Gloucester Pt, Virginia 23062, USA. André W. Droxler, Department of Geology and Geophysics, Rice University, Houston, Texas 77251, USA. how much pelagic carbonate is produced in oceanic surface waters. The following brief discussion of these three topics may point the way toward future directions of individual and group research, but by no means does it preclude the significance of other related subjects.

\section{Global Carbonate Budget}

Calcium carbonate production and accumulation within various neritic and pelagic environments can be calculated by knowing the global area occupied by each environment and the mean rates of carbonate production and accumulation in that environment. All too often, however, calculated global budgets represent no more than crude estimates because of the uncertainty of one or more parameters. In only a few environments do our estimates of production, flux, and accumulation have a $<50 \%$ uncertainty (Table 1). For some environments, such as the pelagic, our estimate of accumulation may be better than our estimate of flux or production. Conversely, carbonate production and accumulation rates on deep-neritic Halimeda mounds and meadows are reasonably well constrained; however global carbonate accumulation remains only a guess because the global area occupied by $\mathrm{Hal}$ imeda mounds is unknown. (Halimeda is a green alga that secretes calcareous plates.)

The least understood carbonate environment in terms of both production and accumulation is probably the continental shelf. Carbonate-poor shelves by definition have little or no significant carbonate accumulation; however the rate of accumulation on carbonate-rich shelves is not well documented. In terms of shelf carbonate production on all shelves, our knowledge has not expanded much beyond Smith's seminal work more than 20 years ago (Smith, 1972). Recent studies have demonstrated that an appreciable portion of neritic carbonates produced on banks and shelves is exported to the deep sea, much of which may be dissolved. Thus, better estimates of shelf production and accumulation (and therefore export) also help our understanding of the pelagic carbonate system. 
Are the Oceans in Steady State?

The estimated present-day carbonate accumulation $\left(32 \times 10^{12}\right.$ moles $\left.y^{-1}\right)$ is 1.5 times the sum of calcium influx from rivers and estimated weathering of mid-ocean ridge crests $\left(21 \times 10^{12} \mathrm{~mol} \mathrm{y}^{-1}\right)$. Although this difference lies within the uncertainty of our calculations, the hypsometry of the ocean basins and the much greater rates of production and accumulation in the neritic environment suggest that steady state is elusive when sea level changes. While neritic and pelagic accumulation are roughly equal at the present high-stand of sea level, lowering sea level by $100 \mathrm{~m}$ (e.g., during the last glacial maximum) would effectively decrease the area of the neritic environment by an order of magnitude. Therefore, to maintain steady state, deep-sea carbonate accumulation must shift substantially in response to changing sea level. However, the few available records suggest that although local patterns of carbonate accumulation have changed considerably during the late Quaternary, mean global accumulation probably has not responded to changing sea level (Milliman, 1993). This suggests a situation in which the increased removal of neritic carbonate during high stands of sea level would lead to a draw-down of the calcium and carbonate reservoirs in the ocean; low stands, on the other hand, would result in less carbonate deposition and a subsequent recharge of the ocean. Geochemical models by D. Archer (unpublished observations) suggest that the carbonate draw-down and corresponding increase in $\mathrm{CO}_{2}$ would result in a shoaling of the lysocline after about 3000-5000 y of highstand. In fact, the lysocline may be presently shoaling in the equatorial Atlantic (François et al., 1990), and subsequent work by François and co-workers suggests a similar occurrence on the Ontong-Java Plateau.

The oceans may approach steady state, however, at a low-stand near $-60 \mathrm{~m}$, when the neritic area (and accumulation?) would be less than onehalf of its present level, and export to the deep sea might be greater. Paleo sea-level curves indicate that median sea level during the last 125,000 $\mathrm{y}$ has been about -50 to $-60 \mathrm{~m}$ (Shackleton and Chappel, 1986), suggesting that for much of this period the oceans may have been in more or less steady state. It is only during excursions to higher or lower sea-level stands, such as the present, that the oceans would deviate significantly from steady state.

One way to resolve the question of steady state is to calculate the global variation in mass accumulation rates (MARs) during glacial and interglacial periods, particularly in the deep sea. If steady state is reached quickly, mean deep-sea accumulation should be markedly greater during low sea level stands than highstands, as the locus of carbonate deposition shifts from the neritic to the pelagic environment. On the other hand, a more or less constant global mean of deep-sea carbonate

Table 1

Estimates (and their relative accuracy) of present-day carbonate flux, production, and accumulation; modified from Milliman (1993)

\begin{tabular}{lcccc}
\hline \multicolumn{1}{c}{ Habitat } & $\begin{array}{c}\text { Area } \\
\left(\times 10^{6} \mathrm{~km}^{2}\right)\end{array}$ & $\begin{array}{c}\mathrm{CaCO}_{3} \mathrm{Flux} \\
\left(\mathrm{g} / \mathrm{m}^{2} \cdot \mathrm{y}^{-1}\right)\end{array}$ & $\begin{array}{c}\mathrm{CaCO}_{3} \text { Prod. } \\
\left(10^{12} \mathrm{~mol} / \mathrm{y}\right)\end{array}$ & $\begin{array}{c}\mathrm{CaCO}_{3} \mathrm{Accum} . \\
\left(10^{12} \mathrm{~mol} / \mathrm{y}\right)\end{array}$ \\
\hline Coral reef complex & $0.60(\mathrm{G})$ & $1.500(\mathrm{G})$ & $9.0(\mathrm{G})$ & $7.0(\mathrm{G})$ \\
Banks/Bays & $0.80(\mathrm{G})$ & $500(\mathrm{~F})$ & $4.0(\mathrm{~F})$ & $2.0(\mathrm{~F})$ \\
Noncarbonate shelves & $15.00(\mathrm{G})$ & $25 ?(\mathrm{P})$ & $4.0 ?(\mathrm{P})$ & $1.0(\mathrm{G})$ \\
Carbonate shelves & $10.00(\mathrm{G})$ & $20-100 ?(\mathrm{P})$ & $6.0 ?(\mathrm{P})$ & $3.0 ?(\mathrm{P})$ \\
$\quad$ Halimeda mounds & $0.05 ?(\mathrm{P})$ & $3.000 ?(\mathrm{~F})$ & $1.5 ?(\mathrm{P})$ & $1.5 ?(\mathrm{P})$ \\
Slopes & $32.00(\mathrm{G})$ & $15(\mathrm{~F})$ & $5.0(\mathrm{~F})$ & $4.0(\mathrm{~F})$ \\
$\quad$ Slopes (imported) & & & $3.5 ?(\mathrm{P})$ & $2.0 ?(\mathrm{P})$ \\
Deep-Sea & $290.00(\mathrm{G})$ & $8(\mathrm{~F}) *$ & $24.0(\mathrm{~F})^{*}$ & $11.0(\mathrm{G})$ \\
$\quad$ & & & $>57.0(?)$ & $32.0(?)$ \\
\hline Total & & & &
\end{tabular}

G: values probably accurate within 50\%; F: values probably accurate within 100\%; P: values with possibly more than $100 \%$ uncertainty. ${ }^{*}$ Calculated pelagic flux at a mean water depth of about $1,000 \mathrm{~m}$.

accumulation with changing sea level would support the concept of the ocean fluctuating between draw-down (highstand) and recharge (lowstand). Unfortunately, to date the few reliable MARs do not allow us to develop a global deep-sea carbonate budget over the last 20-30 ky.

\section{Open Ocean Production and Dissolution: Can We Reconcile Geochemical and Sedimentological Models?}

Based on alkalinity anomalies and the residence times of various water masses, geochemists have calculated that the mean production of pelagic carbonate is about 21-24 $\mathrm{g} \mathrm{m}^{-2} \mathrm{y}^{-1}$ (Morse and MacKenzie, 1990). In contrast, the global mean pelagic carbonate flux at 1,000-m depth measured by long-term sediment traps is about $8 \mathrm{~g} \mathrm{~m}^{-2} \mathrm{y}^{-1}$ (Milliman, 1993). The discrepancy in these two numbers, as pointed out by Wollast (1993), demands explanation. The problem is how to do it.

1. Arguing that the sediment trap data are incorrect or that they have been incorrectly averaged does not seem reasonable. The close correlation between radionuclide and particle flux indicates that sediment traps accurately monitor particle flux where horizontal advection is small (Bacon et al., 1985), suggesting that the fluxes measured by sediment traps at $1,000 \mathrm{~m}$ are accurate. Another way at arriving the same conclusion is that if sediment traps were not effective traps (and if therefore fluxes at $1,000 \mathrm{~m}$ were the $21-24 \mathrm{~g} \mathrm{~m}^{-2} \mathrm{y}^{-1}$ estimated geochemically) dissolution rates on the deep-sea floor would be much higher than any dissolution model would predict: $70 \%$ above the lysocline and $85 \%$ within the lysocline, which clearly is not the case. Because oligotrophic regions have been under-represented by sediment trap experiments, the calculated global flux at $-1000 \mathrm{~m}$ probably is no greater than $10-12$ $\mathrm{g} \mathrm{m}^{-2} \mathrm{y}^{-1}$ and it may even be less than $8 \mathrm{~g} \mathrm{~m}^{-2} \mathrm{y}^{-1}$.

2. Although we are not clear as to how much
The

present-day

carbonate

accumulation is 1.5

times the sum of

calcium influx from

rivers and estimated

weathering of

mid-ocean ridge

crests . . . 
.. shelves do not

seem capable of

producing and

exporting nearly

enough carbonate or

alkalinity-rich waters

to explain the

observed oceanic

alkalinity profiles and

fluxes. carbonate is produced on continental shelves, shelves do not seem capable of producing and exporting nearly enough carbonate or alkalinity-rich waters to explain the observed oceanic alkalinity profiles and fluxes. However, dissolution of bankderived carbonates may explain some of the excess alkalinity observed locally in North Pacific intermediate waters (Sabine and MacKenzie, 1991).

3. Assuming some lateral flux of alkalinity from continental margins, the production of pelagic carbonates in the photosynthetic layer must be about $20 \mathrm{~g} \mathrm{~m}^{-2} \mathrm{y}^{-1}$ to satisfy geochemical models and half or more of the surface production must dissolve in near-surface waters to explain the 8-12 $\mathrm{g} \mathrm{m}^{-2} \mathrm{y}^{-1}$ measured at $1,000 \mathrm{~m}$. In most areas such rapid dissolution in the surface layers must be related to metabolic activities rather than undersaturation in the water column. Although we clearly need a better idea of the levels of carbonate production and dissolution in the oceanic surface layers, moored sediment traps are not the answer, because they tend to over-trap in shallow waters as well as attract swimmers - the reasons, in fact, that most flux measurements are made at greater depths. How one would compare any other measure of surface production with the flux at $1,000 \mathrm{~m}$ then becomes a significant problem.

If the success of a workshop is measured not by how many problems are answered but rather by how many unanswered problems are discussed, our carbonate workshop was an unqualified success, for it clearly defined a number of areas that need particular attention if we are to understand the global carbonate system. Recently the National Science foundation has funded D. Archer and R.
François to measure late Quaternary MARs from about 50 deep-sea cores, which should provide a global data base that permits us to evaluate global pelagic carbonate accumulation over the last $30 \mathrm{ky}$ and thereby address the question of steady state. Initiation of other carbonate studies in shelf and slope environments also is needed.

\section{Acknowledgments}

We thank the 26 participants who contributed through discussions, many of which have continued beyond the actual meeting itself. The Upper Brandon Carbonate Workshop was funded by the National Science Foundation, NSF Grant 9508901.

\section{References}

Bacon, M.P., C.-A. Huh, A.P. Fleer and W.G. Deuser, 1985: Seasonality in the fiux of natural radionuclides and plutonium in the deep Sargasso Sea. Deep-Sea Res., 32, 273-286.

François, R., M.P. Bacon and D.O. Suman, 1990: Thorium 230 profiling in deep-sea sediments: high-resolution records of flux and dissolution of carbonate in the equatorial Atlantic during the last 24,000 years. Paleoceanography, 5, 761-787.

Milliman, J.D., 1993: Production and accumulation of calcium carbonate in the ocean: budget of a nonsteady state. Global Biogeochem. Cycles, 7, 927-957.

Morse, J. and F.T. Mackenzie, 1990: Geochemistry of Sedimentary Carbonates. Elsevier, New York, 707 p.

Sabine, C.L. and F.T. Mackenzie, 1991: Oceanic sinks for anthropogenic $\mathrm{CO}_{2}$. Int. J. Energy, Environ. Econ., l, 119-127.

Shackleton, N.J. and J. Chappell, 1986: Oxygen isotopes and sea level. Nature, 324, 137-139.

Smith, S.V., 1972: Production of calcium carbonate on the mainland shelf of southern California. Limnol. Oceanogr., 17, 28-41.

Wollast, R., 1993: The relative importance of biomineralization and dissolution of $\mathrm{CaCO}_{3}$ in the global carbon cycle. Bull. Inst. Oceanogr. Monaco, Spec. No. 13, 13-35. 